\title{
Evaluating family therapy in a child and adolescent mental health service
}

\author{
Ian Partridge, Carol Redmond, Chris Williams, Jennie Black and \\ Greg Richardson
}

\begin{abstract}
Aims and method Within a mental health service for children and their families a range of treatment options should be offered. We discuss the organisation of family therapy as one mode of treatment within a generic child and adolescent mental health service. It is based upon a review of all referrals during a 12-month period (Aprll 1997-March 1998).

Results This review showed a high rate of nonattendance for first appointments, that the family therapy offered an effective forum for assessment and that a brief focused model of intervention could be effective within a generic service.

Clinical implications This review has lead us to modify our deployment of family therapy as a treatment option: this modification has implications in terms of resource utilisation and of the clinical use of family therapy.
\end{abstract}

Conjoint, supervised family therapy is a labour intensive treatment option, but has particular advantages beyond the therapeutic in that it offers an important systemic training opportunity for junior staff and trainees in all disciplines. However, with limited resources and with increasing demands upon the service as a whole such a provision must be effectively allocated (Roberts \& Partridge, 1998) to ensure clinical relevance. To ensure such relevance and effectiveness as a child and adolescent mental health service (CAMHS) treatment modality it is necessary to address the following issues.

(a) The organisation of family therapy within an existing CAMHS.

(b) The criteria for allocation to family therapy.

(c) User perspectives.

(d) Attendance and re-attendance rates.

(e) Frequency of appointment and length of treatment.

(f) Outcome after one year.

\section{Organisation}

A family therapy team is a Tier 3 provision (NHS Health Advisory Service, 1995) within a CAMHS.
At Lime Trees there are two family therapy teams operating within the community service (a separate team services the in-patient population). Each team operates for one clinical session, an afternoon team offering three appointment times and a morning team offering two appointment times. This offers some flexibility for families with regard to work and school commitments. Both teams are of a multidisciplinary composition. with at least two experienced core members and two regular practitioners as well as professionals in training. The service is coordinated by a senior clinician.

Referrals are received either directly from members of primary health care teams and processed through the allocations team, or indirectly via a member of the CAMHS who has already been involved with the family. The service does not operate a waiting list. A previous service review showed a non-attendance rate of over $40 \%$ with the consequences of under-used clinical time as well as increased waiting times for appointments. At that time $40 \%$ of referrals to family therapy had to wait over 12 weeks for their initial appointment (Roberts \& Partridge, 1998).

\section{Criteria for allocation}

Allocation to a family therapy team should take into account the following clinical and organisational issues:

(a) The nature of the presenting problem and its relation to family functioning.

(b) The structure of the family, including age of the children so that the family therapy intervention can be geared to the developmental level of the children, or the children can be excluded if adult issues need addressing.

(c) The nature and quality of the referral, especially if reference is made to interactional family factors. Further clarification 
from the referrer may be necessary to decide the relevance of family therapy.

(d) The urgency of response required may mean that the family cannot wait for a family therapy appointment. It is, however, recognised that family therapy in a crisis may be effective in helping a family to gain confidence in their own resources rather than them relying on 'help' from outside agencies. However most services would be stretched to provide 'accident and emergency' family therapy.

(e) The availability of alternative responses which may be more effective or economical such as a visit by a community psychiatric nurse to assess willingness to work as a family.

(f) Practical issues for the family such as access to the family therapy base in terms of transport or financial considerations.

(g) Any previous contact with the family by the CAMHS which may inform the decision as to whether family therapy would be a helpful or effective intervention.

(h) The recognised indicators and counterindicators for family therapy (Skynner. 1976; Lask, 1987).

At times, when it was considered economical in terms of time or useful in engaging a family, a pre-assessment interview or contact by a member of the CAMHS has been used to ascertain the appropriateness of family therapy. Consideration of families' expectations and experiences of family therapy is recognised as being important in the overall organisation of the service. Efforts are made to keep the families fully informed at all stages of the process from the information leaflet they receive with their first appointment to decision making regarding discharge. At present we are undertaking a survey of user satisfaction to inform our service delivery from a user perspective.

\section{Attendance/non-attendance rates}

Of the 856 referrals to the CAMHS over the year 1 April 1997 to 31 March 1998, 125 (21.3\%) were allocated to the two family therapy teams. Of those given an initial appointment and asked to confirm $41 \%$ ( $n=51)$ failed to respond or did not attend. This is a high figure and compares unfavourably with the rates found in other studies into attendance rates to CAMHS where non-attendance is less than 20\% (Cottrell et al. 1988; Mason et al, 1995). Of this number only three cases confirmed the appointment and subsequently failed to attend. Once a family had attended for their first appointment the subsequent non-attendance rate was $19 \%(n=9)$. Table 1 shows the outcome after one year.
Table 1. Outcome after one year $(n=124)$

\begin{tabular}{ll}
\hline & $n(\%)$ \\
\hline Did not attend/discharged & $46(37)$ \\
Therapy complete & $37(30)$ \\
Transfer & $24(19)$ \\
Therapy on-going & $17(14)$ \\
\hline
\end{tabular}

\section{Frequency of appointments and length of treatment}

Monthly appointments for out-patient family therapy are routine in busy services, and such frequency is recognised as clinically appropriate. Our service aims at such a frequency. The average wait for an initial appointment was two months and the average for the second appointment was indeed one month.

Family therapy at Lime Trees operates in a brief focused and structural fashion (Minuchin. 1974; de Shazer, 1985, 1988) recognising the importance of meeting service delivery needs. Of the cases seen $34(48 \%)$ were seen on one occasion, $20(26 \%)$ on two occasions, 11 (15\%) on three occasions and on eight (11\%) on four or more occasions. Of cases discharged from family therapy only two were re-referred during the year under review.

\section{Implications}

From this review we would highlight the following points as being important in the organisation and management of such a service.

(a) Clear and explicit criteria for allocation.

(b) Involvement of the families in the process of treatment, with an emphasis upon clear explanations and engagement.

(c) An opt-in system for appointment can reduce waiting times and minimise the non-attendance rates. Families are now sent an appointment after the referral has been processed and are requested to confirm by a certain date and if they fail to confirm they are informed that they will be discharged and the appointment reallocated. Once in therapy if families fail to attend they are sent a standard letter asking as to the reasons for nonattendance and whether they wish another appointment; again a final date for replying is given. It is noted that such a system does increase administrative time. As can be seen a service which operates an opt-in system can reduce the amount of clinical time unused due to non-attendance with the subsequent benefit of shorter waiting times for appointments. It is of note that 
such a system has now been operationalised throughout our CAMHS.

(d) The flexibility to activate alternative resources where appropriate.

(e) A focused, problem solving model of therapy.

(f) On-going evaluation of the service offered both in terms of its structural aspects and its clinical efficacy.

The review has also lead us to reconsider our use and organisation of family therapy in the following areas:

(a) The high rates of non-attendance has lead to reconsideration as to whether the 'cold' allocation to family therapy is appropriate; it may be, that family therapy is perceived as intimidating, that it implies parental 'blame' or that in the view of the parents the CAMHS has misunderstood the referral, which was to 'cure' or 'sort out' the identified patient; therefore, all families who appear from the referral to be suitable for family therapy are now first seen by a member of the team for initial assessment and engagement. The model of initially seeing the whole family if possible is recognised as good practice throughout the service. Additionally, non-attendance rates are lower for individual service members so it may be that families find being seen by a professional rather than a team following referral may be more conducive to their needs. Initial findings from our survey of user perspectives has shown that $44 \%$ would have liked more information about family therapy prior to their arrival, however it is interesting to note that $70 \%$ reported not having read the information sent to them. Again it is recognised that the 'personal touch' may be more effective than the impersonality of written information to a family in 'need' or 'crisis'. However it may also be that referrals arise from transitory crises. Of the cases that were discharged due to non attendance only three $(6 \%)$ were rereferred, during the period under review, suggesting that the problem had subsided or had been dealt with in an alternative manner.

(b) In many cases it is family assessment rather than family therapy that has been offered. The approach to families is now more explicit and the distinctions between seeing a family for family therapy and offering an assessment in a family context is made overt. It is worth noting that the number of cases transferred to other parts of the service can be seen to suggest family therapy as a forum for initial assessment. particularly with regard to complex cases.

(c) These two structural alterations have lead to a reduction in the number of cases to be seen by the family therapy teams and there is a view that although a brief focused and structural approach will be retained, it may be that the number of sessions per family will increase. It is proposed that this situation will continue to be monitored.

\section{Acknowledgement}

We thank Dr Kate Wurr for her help in the preparation of this paper.

\section{References}

Cottrell, D., HiLl. P.. WALK, D., et al (1988) Factors influencing non-attendance at child psychiatry outpatient appointments. British Journal of Psychiatry. 162. 201-204.

DE SHAZER, S. (1985) Keys to Solutions in Brief Therapy. New York: Norton

- (1988) Clues: Investigating Solutions in Brief Therapy. New York: Norton.

LASK. B. (1987) Family therapy. British Medical Joumal 284, 203-204.

MASON, R., WATTS, E. \& HEwISON, J. (1995) Parental expectations of a child and adolescent psychiatric out-patient service. ACPP Review \& Newsletter, 17. 313-322.

MinUCHIN, S. (1974) Families and Family Therapy. London: SSP.

NHS HEALTH ADVISORY SERVICE (1995) Together We Stand The Commissioning. Role and Management of Child and Adolescent Mental Health Services (eds R. Williams \& G. Richardson). London: HMSO.

ROBERTS, S. \& PARTRIDGE. I. (1998) Allocation of referrals within a child and adolescent mental health service. Psychiatric Bulletin, 22, 487-489.

Skynner. A. C. R. (1976) One Flesh: Seperate Persons. London: Constable.

*Ian Partridge, Social Worker, Carol Redmond, Community Psychiatric Nurse, Chris Williams, Clinical Psychologist, Jennie Black, Senior House Officer in Psychiatry, Greg Richardson, Consultant in Child and Adolescent Psychiatry. Lime Trees Child, Adolescent and Family Unit, 31 Shipton Road, York YO3O 5RF

*Correspondence 